Fixed Point Theory, 19(2018), No. 1, 265-274

DOI 10.24193/fpt-ro.2018.1.21

http://www.math.ubbcluj.ro/ nodeacj/sfptcj.html

\title{
SOLUTION OF A PAIR OF NONLINEAR MATRIX EQUATIONS
}

\author{
SK MONOWAR HOSSEIN*, SNEHASISH BOSE** AND KALLOL PAUL** \\ *Department of Mathematics, Aliah University \\ IIA/27 Newtown, Kolkata - 156, West Bengal, India \\ E-mail: sami_milu@yahoo.co.uk \\ ** Department of Mathematics, Jadavpur University \\ Jadavpur-32, West Bengal, India \\ E-mail: bosesonay@gmail.com, kalloldada@gmail.com
}

Abstract. In this paper we consider a pair of nonlinear matrix equations of the form $X=Q_{1}+$ $\left(Y^{*} X Y\right)^{r_{1}}, Y=Q_{2}+\left(X^{*} Y X\right)^{r_{2}}$, where $Q_{1}, Q_{2}$ are $n \times n$ Hermitian positive definite matrices, $r_{1}, r_{2} \in \mathbb{R}$ and prove the existence and uniqueness of positive definite solutions of these equations. We provide an algorithm to approach the solution. We present a coupled fixed point theorem for non-decreasing mapping and show that a particular case of our nonlinear matrix equations also can be solved by using the derived coupled fixed point theorem. Also we show that by replacing $Y$ with $Y^{-1}$ in first equation and $X$ with $X^{-1}$ in second equation and taking $Q_{1}=Q_{2}$ and $r_{1}=r_{2}$, the reduced system can be solved using the coupled fixed point theorem of Berinde [5].

Key Words and Phrases: Fixed point, partially ordered set, matrix equation, Thompson metric. 2010 Mathematics Subject Classification: 15A24, 47H10, 47H09.

Acknowledgments. Sk. Monowar Hossein would like to thank IMSC, Chennai, India for providing research facilities. Snehasish Bose gratefully acknowledges the financial support of CSIR, Govt. of India. The authors also gratefully acknowledge the reviewer for his/her valuable suggestions.

\section{REFERENCES}

[1] A.C.M. Ran, M.C.B. Reurings, A fixed point theorem in partially ordered sets and some applications to matrix equations, Proc. Amer. Math. Soc., 132(2004), no. 5, 1435-1443.

[2] J.J. Nieto, R. Rodriguez-López, Contractive Mapping Theorems in Partially Ordered Sets and Applications to Ordinary Differential Equations, Order, 22(2005), no. 3, 223-239.

[3] D. Guo, V. Lakshmikantham, Coupled fixed points of nonlinear operators with applications, Nonlinear Anal., 11(1987), no. 5, 623-632.

[4] T.G. Bhaskar, V. Lakshmikantham, Fixed point theorems in partially ordered metric spaces and applications, Nonlinear Anal., 65(2006), no. 7, 1379-1393.

[5] V. Berinde, Generalized coupled fixed point theorems for mixed monotone mappings in partially ordered metric spaces, Nonlinear Anal., 74(2011), no. 18, 7347-7355.

[6] M. Bota, A. Petruşel, G. Petruşel, B. Samet, Coupled fixed point theorems for single-valued operators in b-metric spaces, Fixed Point Theory Appl., 2015(2015), no. 1, 231. 
[7] X. Duan, A. Liao, B. Tang, On the nonlinear matrix equation $X-\sum_{i=1}^{m} A_{i}{ }^{*} X^{\delta_{i}} A_{i}=Q$, Linear Algebra Appl., 429(2008), no. 1, 110-121.

[8] Y. Lim, Solving the nonlinear matrix equation $X=Q+\sum_{i=1}^{m} M_{i} X^{\delta_{i}} M_{i}{ }^{*}$ via a contraction principle, Linear Algebra Appl., 430(2009), no. 4, 1380-1383.

[9] X. Duan, A. Liao, On Hermitian positive definite solution of the matrix equation $X=Q+$ $\sum_{i=1}^{m} M_{i} X^{r} M_{i}^{*}$, J. Comput. Appl. Math., 229(2009), no. 1, 27-36.

[10] M. Berzig, B. Samet, Solving systems of nonlinear matrix equations involving Lipschitzian mappings, Fixed Point Theory Appl., 2011(2011), no. 1, 89.

[11] M. Berzig, Solving a class of matrix equations via the Bhaskar-Lakshmikantham coupled fixed point theorem, Appl. Math. Lett., 25(2012), no. 11, 1638-1643.

[12] V.I. Hasanov, Positive definite solutions of the matrix equations $X \pm A^{*} X^{-q} A=Q$, Linear Algebra Appl., 404(2005), 166-182.

[13] Y. Peretz, On applications of Schauder's fixed-point theorem for the solution of the nonsymmetric algebraic Riccati equation, Linear Algebra Appl., 445(2014), 29-55.

[14] A. Sanand, A. Dilip, H.K. Pillai Yet another characterization of solutions of the algebraic Riccati equation, Linear Algebra Appl., 481(2015), 1-35.

[15] A.C. Thompson, On certain contraction mappings in a partially ordered vector space, Proc. Amer. Math. Soc., 14(1963), no. 3, 438-443.

Received: September 2, 2015; Accepted: February 21, 2016. 
